\title{
Not Every Low Back Pain is a Radiculopathy
}

Pankaj Bansal MD, CCFP, Laura Grennan, Karthik Mahadevappa, MBBS, MSc, DM, Emilia Semenov MD, Shanker Nesathurai MD, $\mathrm{MPH}, \mathrm{FRCP}(\mathrm{C})$

\begin{abstract}
About the Authors
Pankaj Bansal MD, CCFP is an Assistant Clinical Professor, Department of Medicine, McMaster University, and Physical Medicine and Rehabilitation, Hamilton Health Sciences. Laura Grennan is an undergraduate student at McMaster University. Karthik Mahadevappa, MBBS, MSc, DM is with the Health Services Authority (HSA), Cayman Islands. Emilia Semenov MD is an Attending Physician, Physical Medicine and Rehabilitation, Whittier Rehabilitation Hospital, Westborough, MA. Shanker Nesathurai MD, MPH, FRCP(C) is a Professor, Division of Physical Medicine and Rehabilitation, Department of Medicine, and Chief and Division Director, Physical Medicine and Rehabilitation and Hamilton Health Sciences.
\end{abstract}

Corresponding Author: Karthik Mahadevappa, MBBS, MSc, DM:

drkarthikm@gmail.com

Submitted: May 6, 2018. Accepted: June 10, 2018. Published: February X, 2019. DOI: 10.22374/cjgim.v14i1.284

A 66-year-old man with a history of chronic low back pain and three previous spine surgical procedures presented with new onset, acute, excruciating low back pain with dysesthesias radiating to the left leg, left leg weakness, and difficulty walking. There were no red flag signs. There was no focal weakness. The left ankle reflex was diminished. Sensation was decreased on the lateral foot, ankle, and lower leg. An acute left S1 radiculopathy was suspected. Magnetic resonance imaging did not reveal any changes from previous.

Three weeks later, a diffuse vesicular rash appeared on his left leg (Figure 1A, 1B, and 1C) without any changes clinically and it was complicated by lumbosacral postherpetic neuralgia ( $\mathrm{PHN}$ ).

Over a period of 2.5 months, the patient was treated with oral acyclovir, tricyclic antidepressants, oxycodone, gabapentin, physical therapy, and TENS (transcutaneous electrical nerve stimulation). His pain improved and he eventually returned to full function.
Herpes zoster can manifest as low back pain and dysesthesias, despite initially suggesting a radiculitis. The most common neurologic complication is postherpetic neuralgia (abnormal sensations and severe, intractable pain or allodynia occurring one month after rash onset). ${ }^{1}$

All persons over 50 years of age and most persons under, should receive an oral antiviral within 72 hours of rash onset. ${ }^{2}$ Adjunctive corticosteroids do not have any effect on quality of life or development of PHN. ${ }^{1}$

\section{References}

1. He L, Zhang D, Zhou M, Zhu C. Corticosteroids for preventing postherpetic neuralgia. Cochrane Database Syst Rev 2008.

2. Kost R, Srause S. Postherpetic neuralgia. Predicting and preventing risk. Arch Intern Med1997;157(11):1166-67
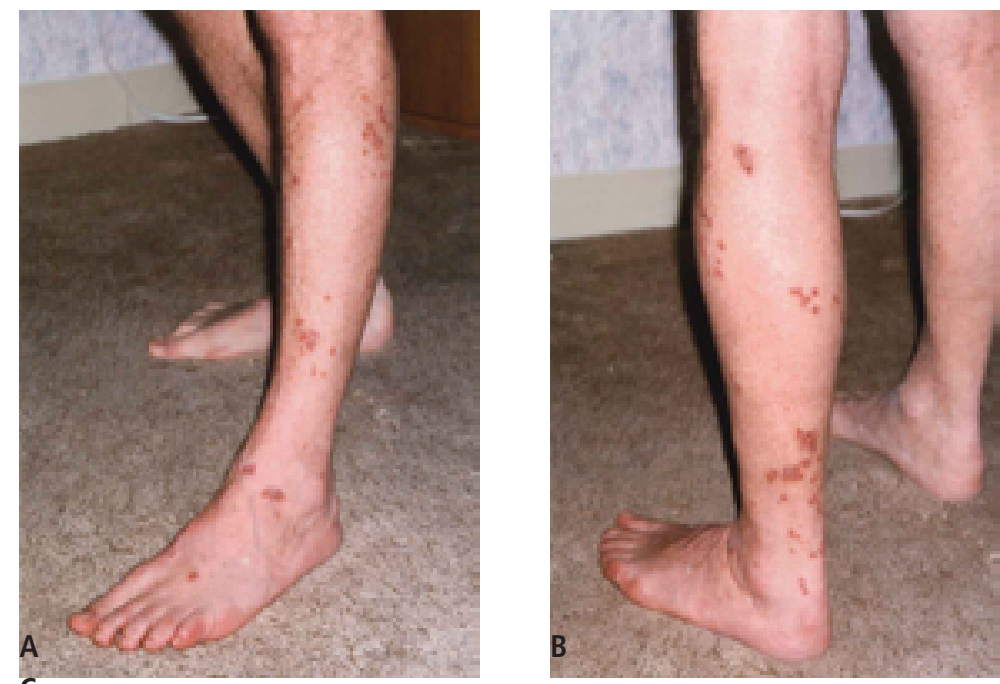

Figure 1. Images of diffuse vesicular rash

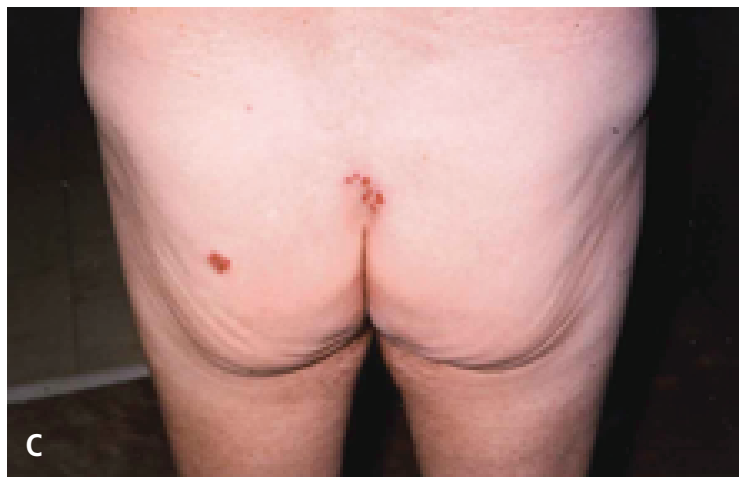

